Research article

urn:1sid:zoobank.org:pub:41346283-D50E-4A52-A6AE-2FA5ED23F1F4

\title{
Two new species of Anamastigona from Cyprus and an updated key to species of the genus (Diplopoda: Chordeumatida: Anthroleucosomatidae)
}

\author{
BOYAN VAGALINSKI ${ }^{1, *} \&$ SERGEI I. GOLOVATCH ${ }^{2}$ \\ ${ }^{1}$ Institute of Biodiversity and Ecosystem Research, Bulgarian Academy of Sciences, \\ 2 Yurii Gagarin Street, 1113, Sofia, Bulgaria. \\ ${ }^{2}$ Institute for Problems of Ecology \& Evolution, Russian Academy of Sciences, \\ Leninsky prospect 33, Moscow 117051, Russia. \\ *Email: boyan_vagalinski@excite.com \\ ${ }^{2}$ Email: sgolovatch@yandex.ru \\ ${ }^{1}$ urn:1sid:zoobank.org:author:973B8725-039E-4F29-8D73-96A7F52CF934 \\ ${ }^{2}$ urn:1sid:zoobank.org:author:71532F45-BDD5-415D-BC54-86256E5D5D4A
}

\begin{abstract}
Two new species of the millipede genus Anamastigona are described, A. cypria sp. nov. and A. strasseri sp. nov., both from the island of Cyprus. The new species are considered to be most similar to A. terraesanctae Golovatch \& Makarov, 2011 from Israel, the three of them forming a species group which is briefly characterized. An updated key to all 20 recognized species of the genus Anamastigona is provided and a short overview of the taxonomy of the genus is given.
\end{abstract}

Keywords. Millipedes, taxonomy, distribution, endemics, synonyms.

Vagalinski B. \& Golovatch S.I. 2016. Two new species of Anamastigona from Cyprus and an updated key to species of the genus (Diplopoda: Chordeumatida: Anthroleucosomatidae). European Journal of Taxonomy 227: 1-19. http://dx.doi.org/10.5852/ejt.2016.227

\section{Introduction}

The millipede genus Anamastigona Silvestri, 1898 (Chordeumatida: Anthroleucosomatidae) is hitherto known to comprise 17-19 species native to the Apennine and Balkan peninsulas, several Mediterranean islands, the northwestern Aegean coast of Turkey, Israel and the Caucasus, with one species, A. pulchella (Silvestri, 1894), showing a broader, scattered distribution across western Europe, probably a result of human activity.

The name Anamastigona has a long history dating back to Silvestri (1898), followed by numerous, mostly single-species descriptions and redescriptions by various authors, until the last two members of the genus - A. mauriesi and A. terraesanctae - were described by Golovatch \& Makarov (2011). The latest comprehensive work on the genus in the framework of a review of the family Anthroleucosomatidae is that by Ćurčić et al. (2008). These authors presented a key to the species of Anamastigona, as part of a key to the genera and species of Anthroleucosomatidae, and suspected that A. aspromontis (Strasser, 
1970) and A. halophila Verhoeff, 1940 were junior synonyms of A. meridionalis Silvestri, 1898 and A. bilselii (Verhoeff, 1940), respectively; both of those synonymies were formally proposed later by Golovatch \& Makarov (2011). However, comparison of the original drawings of $A$. meridionalis and $A$. aspromontis reveals considerable differences between the two species, making their synonymy rather unlikely (see also Discussion). The synonymy of A. halophila with A. bilselii seems quite probable considering the known distribution of $A$. bilselii, but nevertheless a direct comparison of type material is needed to secure the synonymy in question.

The present study adds another two species to Anamastigona, currently representing the only known members of the genus and of the order Chordeumatida in general from Cyprus (Vagalinski et al. 2014). The existence of the two new species fills in the geographical gap between the Aegean islands and Israel within the distribution range of Anamastigona. Considering the increased number of species recognized in Anamastigona, an updated key is provided, in which a total of 20 species is recognized.

\section{Material and methods}

All specimens are preserved in 70\% ethanol. Gonopods, legs, antennae and vulvae of some specimens were dissected and mounted on permanent euparal or eukitt slides and observed under an Olympus BX51 light microscope. Colour micrographs were taken with the aid of a Carl Zeiss Discovery V8 stereo microscope, with a Nikon Coolpix S3700 camera mounted on one of the eyepieces. SEM pictures were obtained with a JEOL JSM-5510 scanning electron microscope after sputter-coating of the prepared body parts with gold-palladium.

The descriptions of the new species mostly follow the pattern of Golovatch \& Makarov (2011). Terminology of the gonopod parts and the metrical indices are after Ćurčić et al. (2008) and Golovatch \& Makarov (2011), with minor changes.

Abbreviations used:

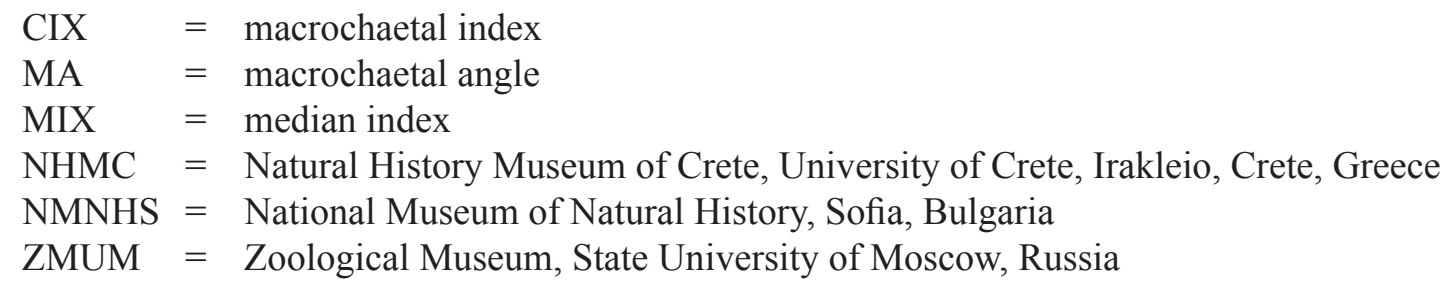

\section{Results}

Class Diplopoda Blainville-Gervais, 1844

Order Chordeumatida Koch, 1847

Family Anthroleucosomatidae Verhoeff, 1899

Genus Anamastigona Silvestri, 1898

Anamastigona Silvestri, 1898: 661. Type species: Craspedosoma pulchellum Silvestri 1894: 199, by original designation.

Prodicus Attems, 1899: 317.

Hellasdicus Verhoeff, 1940a: 273.

Paraprodicus Verhoeff, 1940b: 24.

Balkandicus Strasser, 1960: 112.

Osmandicus Strasser, 1960: 105.

Antrodicus Gulička, 1967: 2. 


\section{Diagnosis}

A genus of the family Anthroleucosomatidae characterized by a body consisting of 29 segments plus the telson and by the following gonopodal characters: caudal face of anterior gonopods with lamellar central part, but without well-developed syncoxite, and with colpoxites; posterior gonopods with welldeveloped, strongly chitinized angiocoxites and with usually more or less membranous colpoxites.

\section{Anamastigona cypria sp. nov. urn:1sid:zoobank.org:act:FD1105FF-4E6D-4851-A5B6-477FFDD8DFD2}

Figs 1-3

Anamastigona sp. 1 - Vagalinski et al. 2014: 540, fig. 12.

\section{Diagnosis}

Resembles its most similar congeners - A. terraesanctae and A. strasseri sp. nov. - by the anterior gonopods possessing well-developed colpocoxites and an elaborate median lamella, which is more or less densely covered with long, setiform filaments; and by the posterior gonopods consisting of large, relatively stout angiocoxites, bearing several setae and rather prominent telopodital rudiments, and of fine, membranous colpocoxites. Differs from them by being on average slightly smaller, with a somewhat darker colouration, and by certain details of gonopod structure, namely, the lateral arms of the anterior gonopods branching distally into 2 processes and by the presence of a subapical unciform process on the angiocoxites of the posterior gonopods; further morphological differences between the 3 species are summarized in Table 1.

\section{Etymology}

The epithet of this new species emphasizes its provenance from Cyprus.

\section{Type material}

\section{Holotype}

CYPRUS: $\widehat{\partial}$ (intact), FC0022, Nicosia, Pediaios, stream under Eucalyptus, S4, 27 Nov. 2011-15 Jan. 2012, pitfall traps, Simaiakis, Stylianou \& Tambouri leg. (NHMC).

\section{Paratypes}

CYPRUS: $3 \curvearrowright \widehat{~(i n t a c t, ~} 1$ half-broken in the caudal part), $1 q$ (with heavily damaged and fragmented head and front body, right vulva mounted on slide), same sample as holotype (NHMC); 1 त (in 2 pieces, with broken distal parts of antennae, gonopods mounted for SEM), FC0060, Nicosia, Troodos Mts, $4 \mathrm{~km}$ before Prodromos square, pine forest next to the road, $1305 \mathrm{~m}, 11$ Feb.-19 Mar. 2012, pitfall traps, Simaiakis leg. (NHMC); 1 đ (in 2 pieces, gonopods dissected), FC0019, Nicosia, Athalassas Park South, corridors with Eucalyptus, S1, 27 Nov. 2011-15 Jan. 2012, pitfall traps, Simaiakis, Stylianou \& Tambouri leg. (ZMUM); 2 ठิ $\widehat{\text { ( }}$ (one dissected, in 2 parts + pleurotergum 7, with gonopods mounted for SEM, the other into head, collum and 3 body pieces; gonopods, antenna, legs 1, 3, 5, 7 and 15 mounted on slide), FC0009, Troodos Mts, $2.5 \mathrm{~km}$ after Prodromos square, mixed pine forest, $1615 \mathrm{~m}, 18$ Oct.-26 Nov. 2011, pitfall traps, Simaiakis \& Louca leg. (NMNHS).

\section{Description}

MEASUREMENTS. With 30 segments including telson, with 1-2 legless segments; males $7.2-9.2 \mathrm{~mm}$ in length, $0.6-0.65$ in height at mid-body and $0.75-0.8 \mathrm{~mm}$ maximal width; holotype $9.1 \mathrm{~mm}$ long; the female somewhat longer than the males (exact length impossible to measure due to the damaged frontal part), $0.75 \mathrm{~mm}$ high at mid-body, $0.95 \mathrm{~mm}$ maximal width (at segments 25-26). 
Colouration. Visibly faded on most specimens. Mostly brown, with scattered, small, bright spots and veins, giving a marble-like pattern to the tegument; prozonae on posterior segments dorsally blackish; with smaller, oval, bright spots just above shoulders; sterna yellowish-beige; legs beige to light brown.

EXTERNAL STRUCTURES. Tegument smooth, only hind margins of pleuroterga very finely and sparsely striated dorsally. Head with $20-24$ ocelli, arranged in 8 oblique rows: $1+1+2+3+4+4(5)+3(4,5)+2(3)$, counting from hind lower corner of ocellarium. Head moderately setose: vertex, frons, labrum and mandibular cardines more or less evenly covered with short, stout setae, these latter being somewhat longer on labrum and distal part of frons. Frons in males flat to gently convex. Antennae (Fig. 2A) almost 2 times as long as head; antennomeres 2 and 4 subequal, somewhat longer than 6 , antennomere 3 ca 2 times longer than 4, slightly shorter than antennomere 5. Labrum with 3 small, rounded marginal teeth. Gnathochilarium with a rather large, broad, subtriangular promentum, about half as long as stipites. Collum smooth, without median groove. In width, collum $<$ segment $2<3<4<$ head $\approx 5 \approx 8-18(19)<6 \approx 7$ (males), after segment 19 increasingly narrowed towards telson. Axial
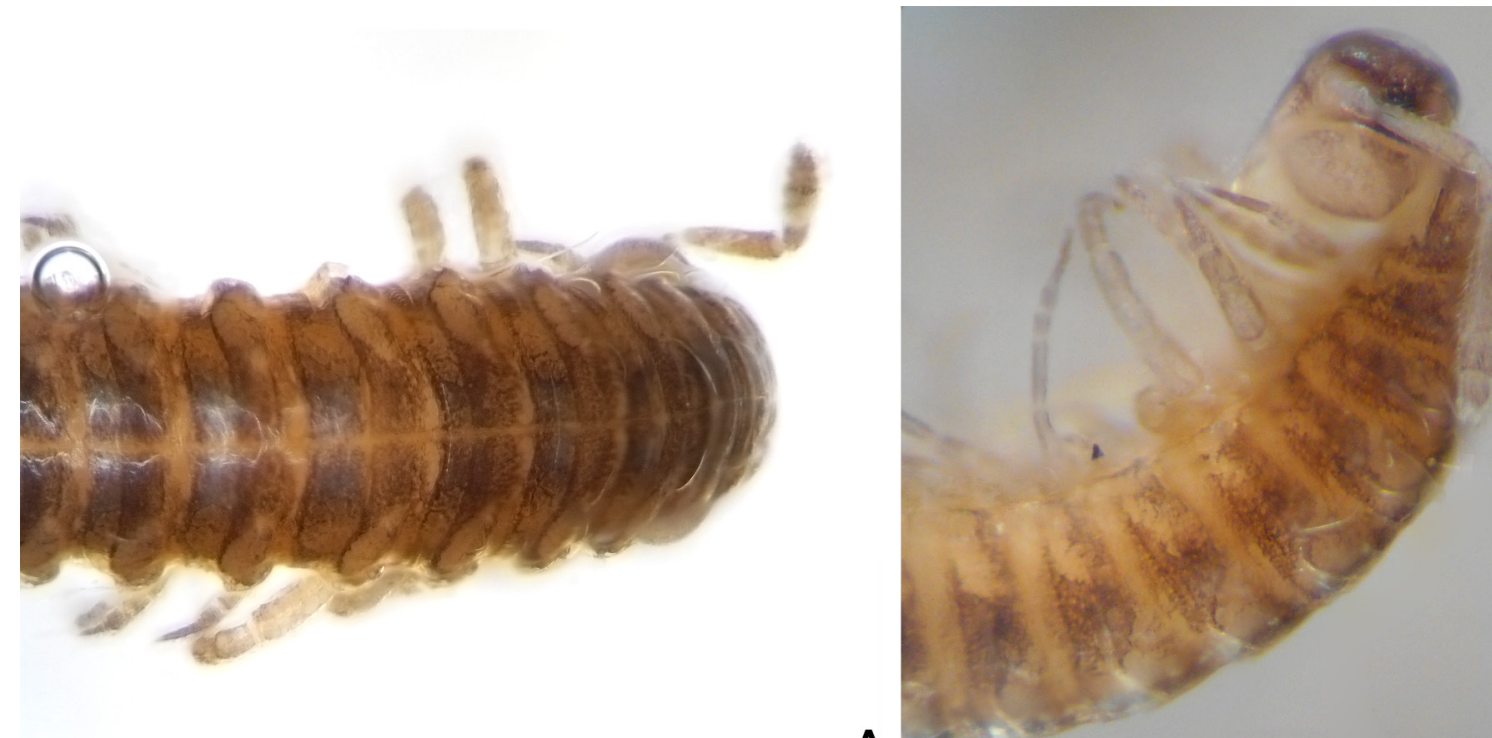

A
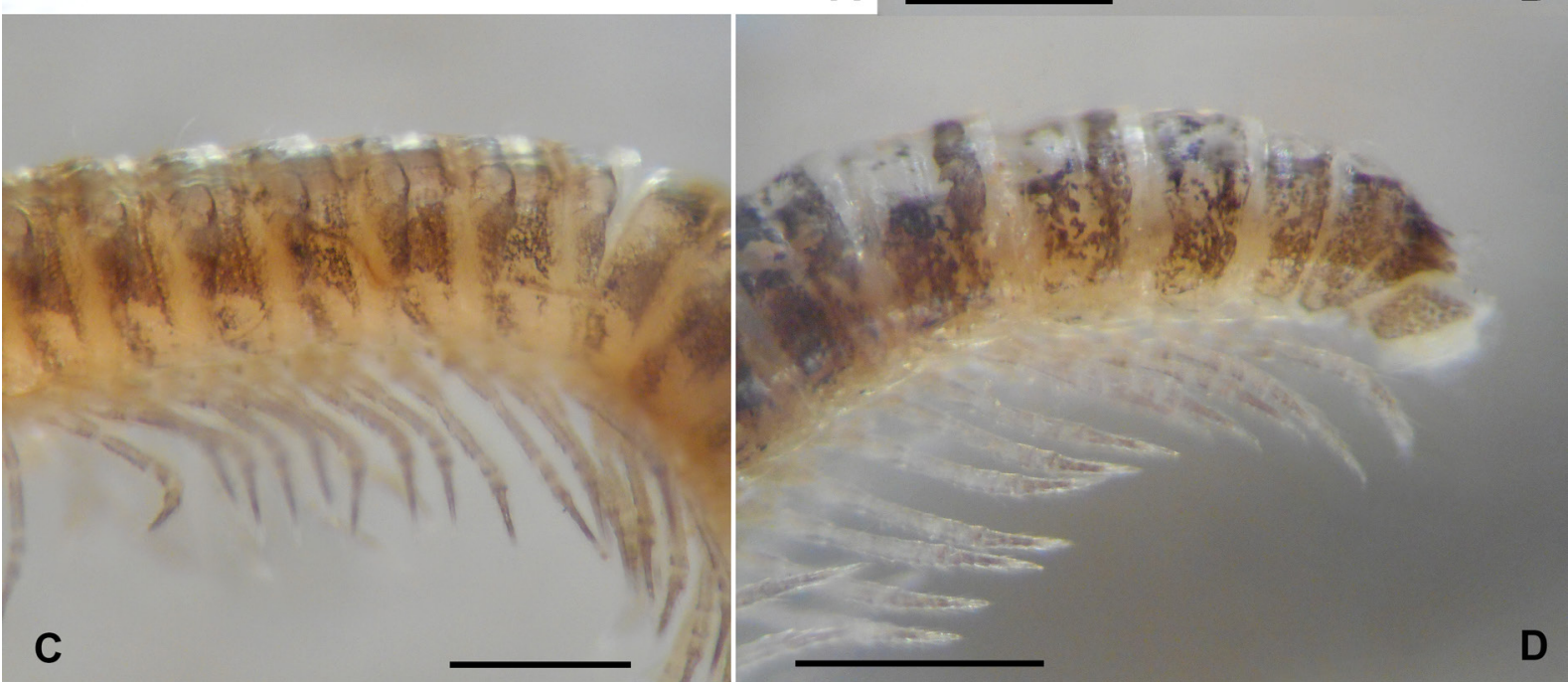

Fig. 1. External habitus of Anamastigona cypria sp. nov., đ̊̃, paratype from Nicosia, Pediaios. A. Anterior part of body, dorsal view. B. Anterior part of body, lateral view. C. Middle part of body, lateral view. D. Posterior part of body, lateral view. Scale bars $=0.5 \mathrm{~mm}$. 
suture well-developed, narrow. Stricture between pro- and metazonae quite wide and rather shallow. Paraterga small, somewhat edgy dorso-lateral swellings, forming a mild ridge between lateral and median macrochaetae; most prominent on segments $8-19$, then gradually diminishing towards telson, completely disappearing on segments 28 and 29 . Metatergal setation typical, macrochaetae $0.12-0.2 \mathrm{~mm}$ long, on same segment more or less equal in length; CIX $(15) \approx 0.5-0.6$, MIX (15) $\approx 1.3$, MA (15) $\approx 135-145^{\circ}$. Pleurotergum 7 unmodified. Epiproct short, broad, truncated caudally, with a straight to
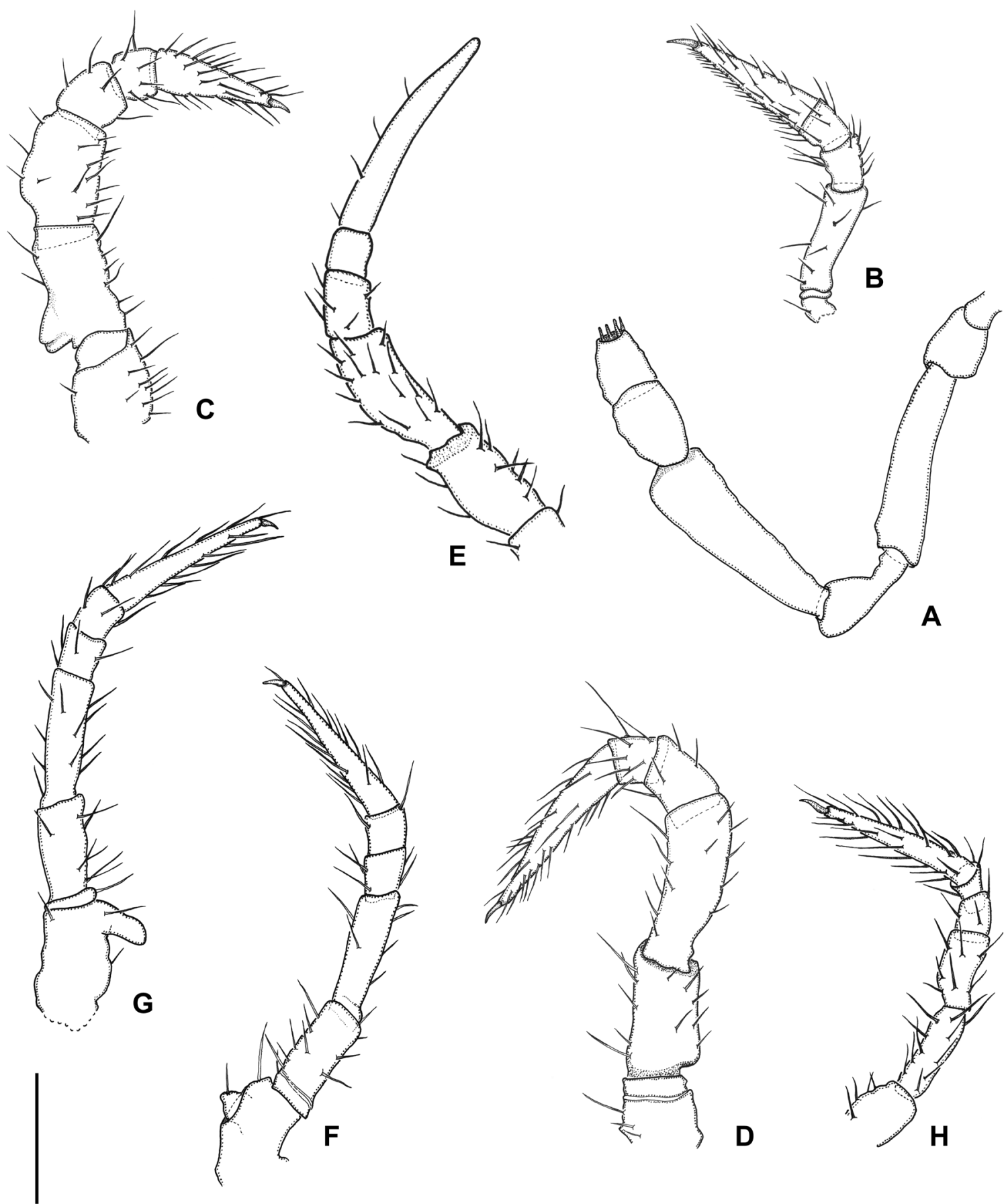

Fig. 2. Non-gonopodal characters of Anamastigona cypria sp. nov., $\widehat{\jmath} \widehat{\jmath}$, paratypes. A. Antenna (setae omitted). B. Leg 1. C. Leg 3. D. Leg 5. E. Leg 7 (claw broken off). F. Leg 10. G. Leg 11. H. Leg 24. Scale bar $=0.2 \mathrm{~mm}$. 

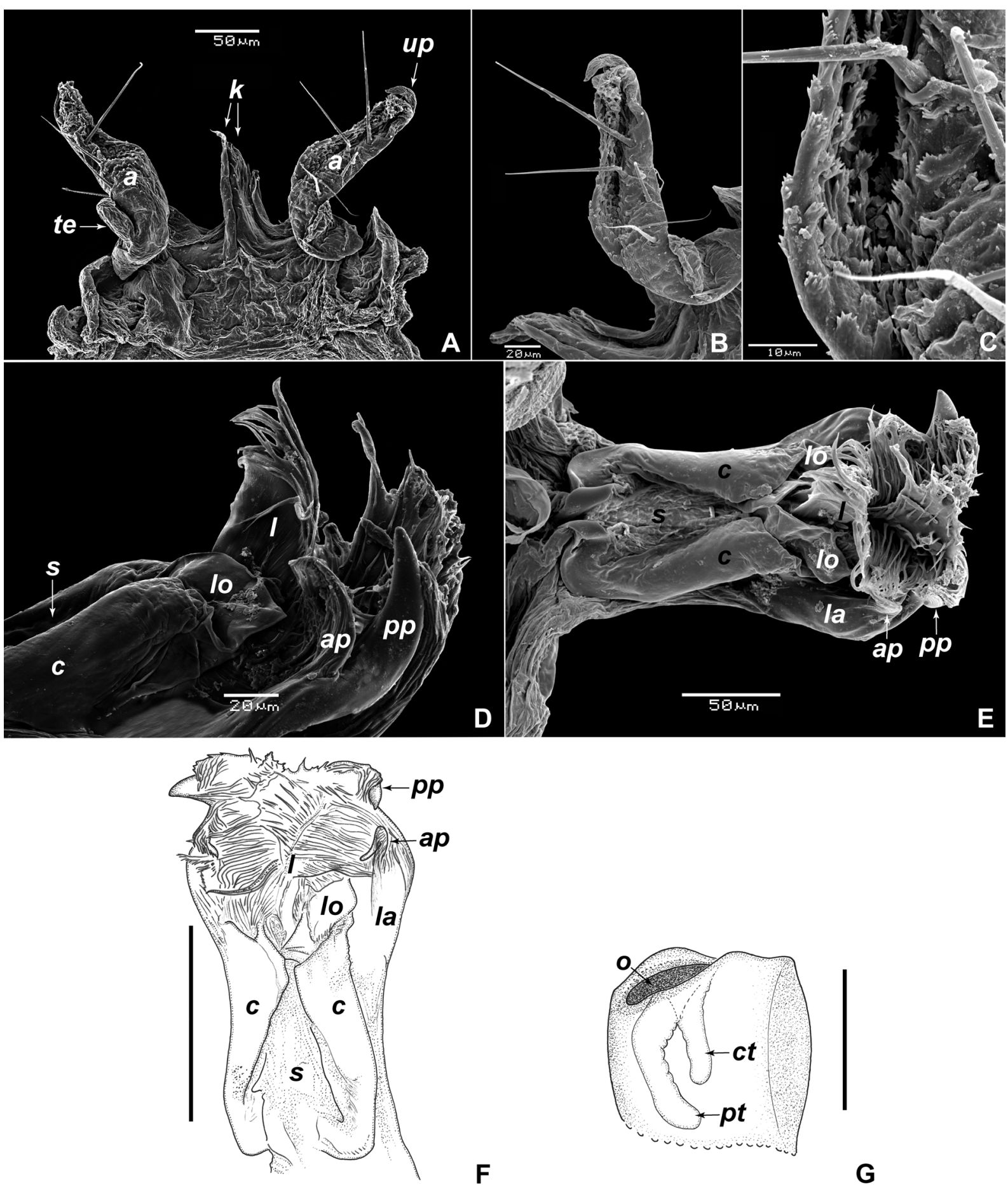

$\mathbf{F}$

G

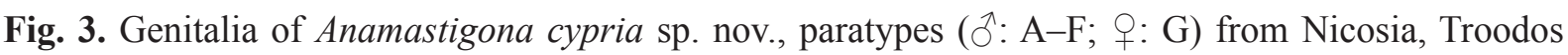
Mts, $4 \mathrm{~km}$ before Prodromos square. A. Posterior gonopods, caudal view. B. Left angiocoxite of the posterior gonopods, caudal view. C. Same aspect, mid-part strongly magnified. D. Anterior gonopods, lateral view. E. Anterior gonopods, caudal, slightly lateral view. F. Same aspect. G. Left vulva, caudal view (setae omitted; receptaculum seminis seen by transparency, but drawn with solid lines for better emphasis). Abbreviations: $a=$ angiocoxite; $a p=$ anterior process; $c=$ colpoxites of anterior gonopods; $c t=$ central tube; $l=$ lamellar median part; $l a=$ lateral arm; $l o=$ lamellar outgrowth; $k=$ colpoxites of posterior gonopods; $o=$ opening; $p p=$ posterior process; $p t=$ posterior tube; $s=$ central depression; $t e=$ telopodital rudiment; $u p=$ unciform process. Scale bars (drawings) $=0.1 \mathrm{~mm}$. 
slightly rounded caudal margin; medially with a pair of two long setae, distally with a row of 7 short setae. Paraprocts with 3 long marginal setae each. Hypoproct semi-elliptic, with 3 long marginal setae.

Male LEGs. Pairs 1 (Fig. 2B) and 2 significantly shorter and thinner than following ones, mesally with fine, short setae, forming tarsal brushes; coxa 2 ventrally with a gland opening; pairs 3 (Fig. 2C) and 4 conspicuously thick, each with a stout, shortly bifurcated bump dorso-parabasally on prefemur; 5-7 increasingly longer, 5 (Fig. 2D) with a short, thorn-like process anteriorly on prefemur, 7 (Fig. 2E) with an extremely long tarsus, the latter more than 2 times as long as postfemur + tibia; coxa 10 (Fig. 2F) ventrally with small tubercle protruding from gland opening; coxa 11 (Fig. 2G) ventrally with blunt process; following pairs without modifications; leg 24 (Fig. $2 \mathrm{H}$ ) 1.25-1.4 times as long as mid-body height, its tarsus 1.8-1.9 times longer than postfemur + tibia.

Gonopods (Fig. 3A-F). Anterior gonopods (Fig. 3D-F) fused in their proximal parts, consisting of two lateral arms $(\boldsymbol{l a})$, each divided distally into two processes - a larger posterior $(\boldsymbol{p p})$ and a smaller anterior one ( $\boldsymbol{a} \boldsymbol{p})$, both processes tapering and bent caudad; a lamellar median part $(\boldsymbol{l})$, densely covered with long setiform filaments; and two elongated colpocoxites $(\boldsymbol{c})$, each ending apically as lamellar outgrowths $(\boldsymbol{l o})$, basally surrounding a subtriangular central depression (s). Posterior gonopods (Fig. 3A-B) reduced; angiocoxites $(\boldsymbol{a})$ elongated, relatively stout, somewhat tapering, subapically bearing thin, unciform process ( up ) bent caudad, caudal face microsquamate, bearing several setae; telopodital rudiments (te) lobe-like, pigmented, positioned caudo-laterobasally on $\boldsymbol{a}$; colpoxites $(\boldsymbol{k})$ placed close to each other, considerably shorter than $\boldsymbol{a}$, slender, weakly chitinized.

Vulva (Fig. 3G). Compact, box-like, somewhat meso-laterally compressed; opening (o) positioned mostly apically on bursa, narrow; operculum equal to bursa, with shallowly bifurcated apex; setation rather short, present only on distal parts of bursa and operculum. Receptaculum seminis double, consisting of larger, somewhat bent posterior tube $(\boldsymbol{p t})$ and smaller, more or less straight central tube (ct).

\section{Anamastigona strasseri sp. nov. urn:1sid:zoobank.org:act:07A0082F-06B5-4078-96C1-4B0A9B3DA43B}

Figs 4-6

Anamastigona sp. 2 - Vagalinski et al. 2014: 541, fig. 12.

\section{Diagnosis}

Resembles its most similar congeners - A. terraesanctae and A. cypria sp. nov. - by the anterior gonopods possessing well-developed colpocoxites, and an elaborate median lamella, which is more or less densely covered with long, setiform filaments; and by the posterior gonopods consisting of large, relatively stout angiocoxites, bearing several setae and rather prominent telopodital rudiments, and of fine, membranous colpocoxites. Differs from them mostly by the lateral arms of the anterior gonopods being blunt and barely bent caudad, rather than tapering and strongly bent caudad. Further morphological differences between the 3 species are summarized in Table 1 .

\section{Etymology}

This species is named in memory of Karl Strasser (1903-1981), a prominent myriapodologist who, among other things, described several species of Anamastigona.

\section{Type material}

\section{Holotype}

CYPRUS: 0 (in 3 parts: head + first 6 segments, segment 7 and rest of body; half-broken behind segment 18), FC0003, Paphos, Pano Panagia village, next to a winery, patches with Eucalyptus, $800 \mathrm{~m}$, hand collection, 8 Nov. 2011, S. Simaiakis leg. (NHMC). 


\section{Description}

MEasurements. Body segments $28+1+\mathrm{T}, 8.2 \mathrm{~mm}$ long, $0.7 \mathrm{~mm}$ high at mid-body, $0.85 \mathrm{~mm}$ maximal width.

Colouration. Marbled brownish (somewhat more contrasting compared to A. cypria sp. nov.), more intense on posterior half of body; with blackish transverse stripes dorsally on prozonae; ventral side and legs beige to light brown; large, light, cloud-like spots present dorso-laterally just above shoulders.

EXTERNAL STRUCTURES. Tegument smooth, only hind margins of pleuroterga finely striolate dorsally. Head with 19-20 blackish ocelli arranged in 8 oblique rows: $1+1+2+3(2)+3+4+3(4)+2(3)$, counting from hind lower corner of ocellarium. Head rather sparsely setose: vertex and upper part of frons bare,

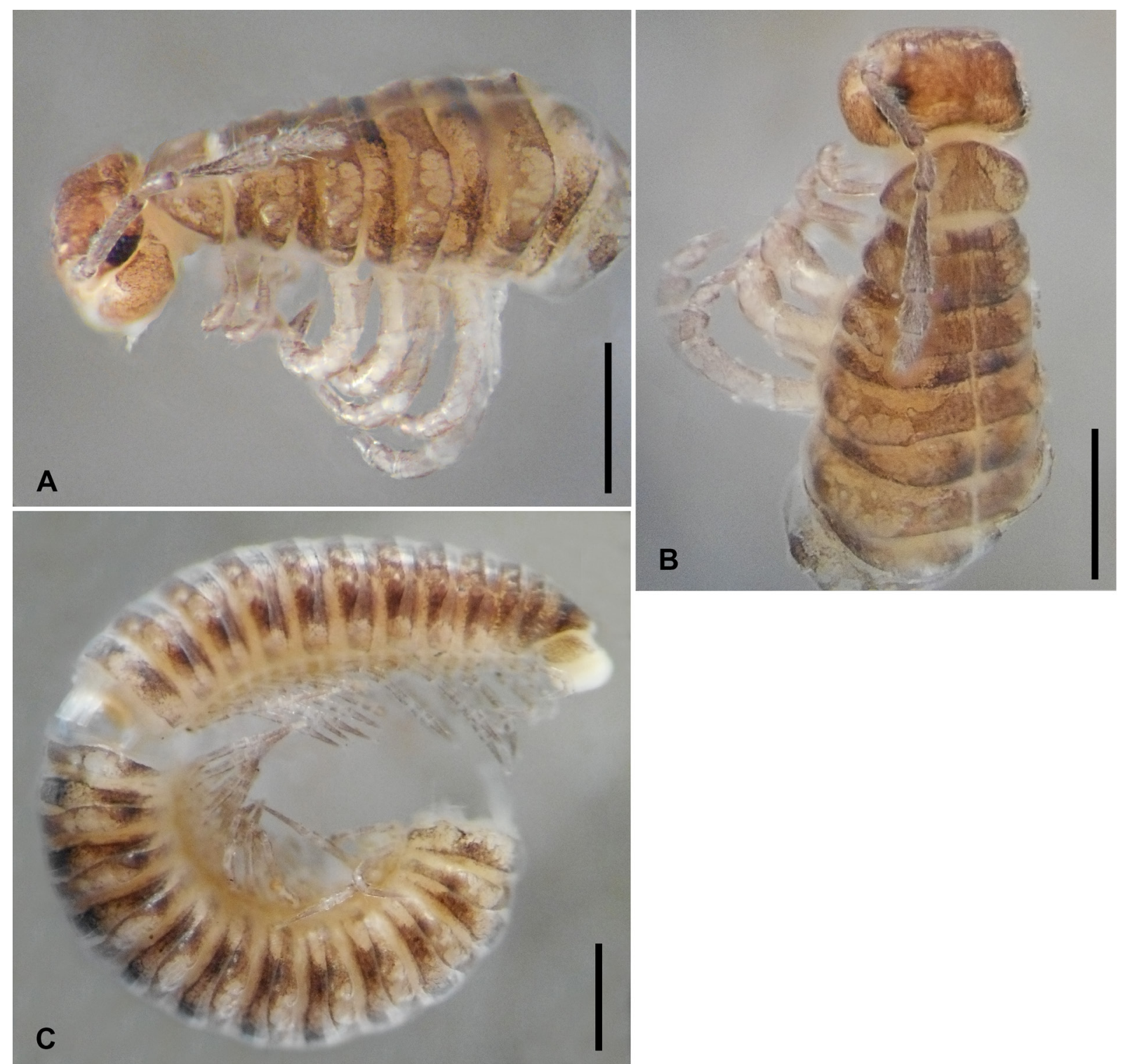

Fig. 4. External habitus of Anamastigona strasseri sp. nov., Ô, holotype. A. Head with first 7 segments, lateral, slightly dorsal view. B. Head with first 7 segments, dorsal, slightly lateral view. C. Segment 8 to telson, lateral view. Scale bars $=0.5 \mathrm{~mm}$. 
lower part of frons and labrum moderately densely covered with two types of setae - some very short ones, the others ca 2 times as long; several very short setae on occiput. Frons flat or very gently convex. Antennae almost 2 times as long as head; antennomeres 2, 4 and 6 subequal, antennomere 3 ca 2 times longer, slightly shorter than antennomere 5. Labrum tridentate. Gnathochilarium with rather large, triangular, somewhat broader than long promentum; stipites with several long lateral setae. Collum with median longitudinal groove. In width, collum $<$ segment $2<$ head $\approx 3<4<5 \approx 8-18(19)<6<7$; after segment 19 increasingly narrowed towards telson. Axial suture well-developed, thin. Stricture between pro- and metazonae quite broad and rather shallow. Paraterga small, rounded, dorsolateral swellings, most prominent on segments $8-19$, then gradually diminishing towards telson, completely disappearing on segments 28 and 29. Metatergal setation typical (macrochaetae mostly broken off), macrochaetae $0.2-0.25 \mathrm{~mm}$ long. CIX $(15) \approx 0.6$, MIX $(15) \approx 1.6$, MA $(15) \approx 135^{\circ}$. Pleurotergum 7 almost unmodified, its ventral margin forming very low ridge. Epiproct truncated caudally, caudal margin with several small, rounded, scale-like protuberances. Each paraproct with single long marginal seta. Hypoproct semi-elliptic, with two long marginal setae.

LEGS. Pairs 1 and 2 shortest, with very thin prefemur and femur, mesally with tarsal brushes; coxa 2 with gland opening; pairs 3 and 4 (Fig. 5A) very thick, with stout, shortly bifurcated bump dorso-parabasally on prefemur; 5-7 increasingly longer, tarsus of 7 (Fig. 5B) very long, ca 1.6 times as long as postfemur + tibia; coxa 10 (Fig. 5C) ventrally expanding into cylindrical process, expanding apically into somewhat curved, foam-like protrusion; coxa 11 (Fig. 5D) with two processes: a proximal, ventral one, similar to that on coxa 10, the other a distal, ventro-anterior, short and blunt, process; leg 24 ca 1.3 times as long as mid-body height, its tarsus ca 2 times as long as postfemur + tibia.

Gonopods (Fig. 6A-D). Anterior gonopods (Fig. 6A-B) similar to those of A. cypria sp. nov., the main difference being the lateral arms $(\boldsymbol{l a})$, which are uniramous, apically blunt/narrowly rounded, barely bent caudad. Posterior gonopods (Fig. 6C-D) reduced; angiocoxites (a) stout, flattened apically, microsquamate, caudo-laterally with several setae; telopodital rudiments $(\boldsymbol{t e})$ short, rounded, composed of 2 articles, pigmented, positioned caudo-latero-parabasally on $\boldsymbol{a}$; colpoxites $(\boldsymbol{k})$ placed almost one behind the other rather than side by side, slender, somewhat lower than $\boldsymbol{a}$.
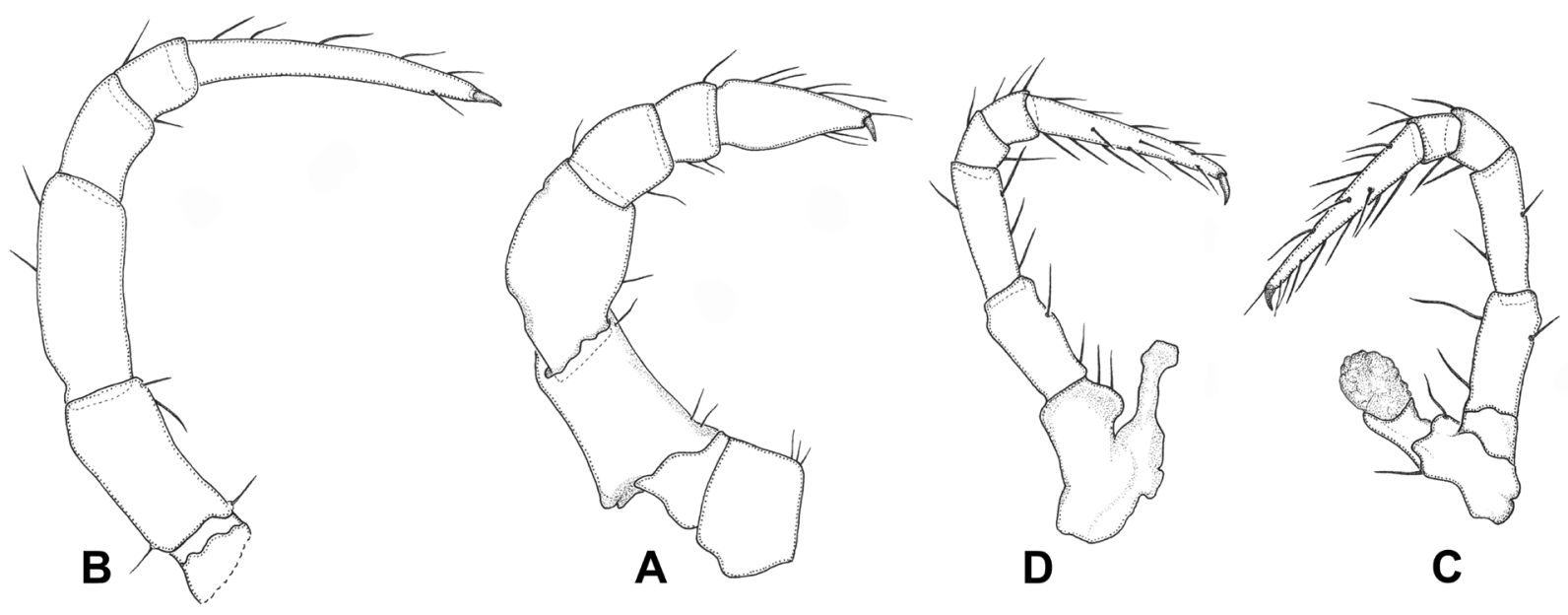

Fig. 5. Legs of Anamastigona strasseri sp. nov., đ̂, holotype. A. Leg 4. B. Leg 7. C. Leg 10. D. Leg 11. Scale bar $=0.2 \mathrm{~mm}$. 


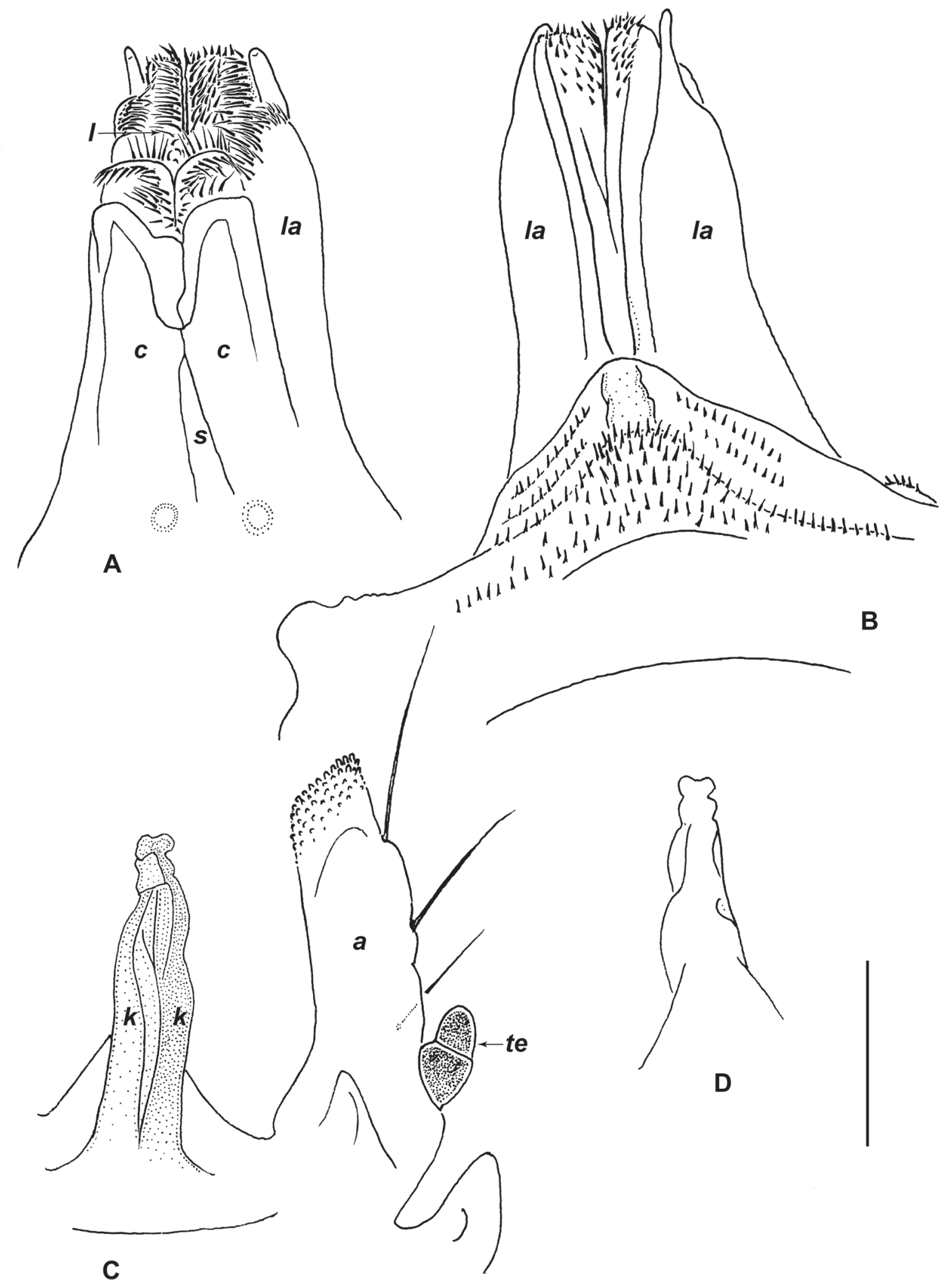

Fig. 6. Gonopods of Anamastigona strasseri sp. nov., đ, holotype. A. Anterior gonopods, caudal, slightly lateral view. B. Anterior gonopods, frontal, slightly lateral view. C. Posterior gonopods, frontal view. D. Right colpoxite of posterior gonopods, caudal view. Abbreviations as in Fig. 3. Scale bar $=0.1 \mathrm{~mm}$. 
Table 1. Diagnostic characters of Anamastigona cypria sp. nov., A. strasseri sp. nov. and A. terraesanctae Golovatch \& Makarov, 2011.

\begin{tabular}{lccc}
\hline & A. cypria sp. nov. & A. strasseri sp. nov. & A. terraesanctae \\
\hline $\begin{array}{l}\text { Lateral arms of } \\
\text { anterior gonopods }\end{array}$ & $\begin{array}{c}\text { distally divided into } \\
\text { 2 processes }\end{array}$ & uniramous & uniramous \\
\hline $\begin{array}{l}\text { Angiocoxites of } \\
\text { posterior gonopods }\end{array}$ & $\begin{array}{c}\text { subapically bearing an } \\
\text { unciform process }\end{array}$ & $\begin{array}{c}\text { ending blunt, without } \\
\text { processes }\end{array}$ & $\begin{array}{c}\text { subapically bearing a } \\
\text { finger-like process }\end{array}$ \\
\hline Head & broader than segment 2 & broader than segment 2 & $\begin{array}{c}\text { more narrow than } \\
\text { segment 2 }\end{array}$ \\
\hline Collum & without groove & with a median groove & without groove \\
\hline MIX & 1.3 & 1.6 & 1.3 \\
\hline $\begin{array}{l}\text { Marginal setae on } \\
\text { each paraproct }\end{array}$ & 3 & 1 & 3 \\
\hline $\begin{array}{l}\text { Marginal setae on } \\
\text { hypoproct }\end{array}$ & 3 & 2 & 2 \\
\hline Tarsus 7 & $\begin{array}{c}\text { ca 2 times as long as } \\
\text { postfemur + tibia }\end{array}$ & $\begin{array}{c}\text { ca 1.6 times as long as } \\
\text { postfemur + tibia }\end{array}$ & $\begin{array}{c}\text { ca 2 times as long as } \\
\text { postfemur + tibia }\end{array}$ \\
\hline $\begin{array}{c}\text { with a small tubercle } \\
\text { protruding from a gland } \\
\text { opening }\end{array}$ & $\begin{array}{c}\text { with a process ending in a } \\
\text { foam-like protrusion }\end{array}$ & $\begin{array}{c}\text { with a gland opening; } \\
\text { without processes }\end{array}$ \\
\hline
\end{tabular}

\section{Remarks}

The position of the posterior gonopod colpocoxites in this species is unusual - they are almost completely oriented one behind the other, rather than next to each other, i.e., more perpendicular than parallel to the sternal axis. However, in the presence of only one examined male, this peculiarity may represent nothing more than individual variation.

\section{Comparative material}

Anamastigona terraesanctae Golovatch \& Makarov, 2011

Fig. 7

\section{Material examined}

ISRAEL: 1 ô (gonopods prepared for SEM), 2 q $q$, Shuni Park, $1 \mathrm{~km} \mathrm{~N}$ of Binyamina, 32 $32^{\prime} \mathrm{N}, 34^{\circ} 57^{\prime} \mathrm{E}$, $60 \mathrm{~m}$ a.s.l., date unknown, Yu. Marusik leg. (ZMUM).

\section{Remarks}

Gonopods (Fig. 7A-E). Anterior gonopods (Fig. 7C-E) consisting of two lateral, uniramous arms $(\boldsymbol{l a})$, ending with strongly bent, unciform tips; a lamellar median part (l), relatively sparsely covered with setiform filaments; and two robust colpocoxites $(\boldsymbol{c})$, basally surrounding a subtriangular central depression (s). Posterior gonopods (Fig. 7A-B) consisting of stout, clavate angiocoxites (a), caudolatero-basally bearing short, rounded telopodital rudiments (te); and of slender, weakly chitinized colpoxites $(\boldsymbol{k})$. 


\section{Key to known species of Anamastigona based on gonopodal characters}

1. Posterior gonopods with telopodital rudiments

- Posterior gonopods either without telopodital rudiments or these only represented by pigmented spots

2. Telopodital rudiments of posterior gonopods positioned apically on angiocoxites

A. mauriesi Golovatch \& Makarov, 2011

- Telopodital rudiments of posterior gonopods positioned basally/parabasally on angiocoxites ........3

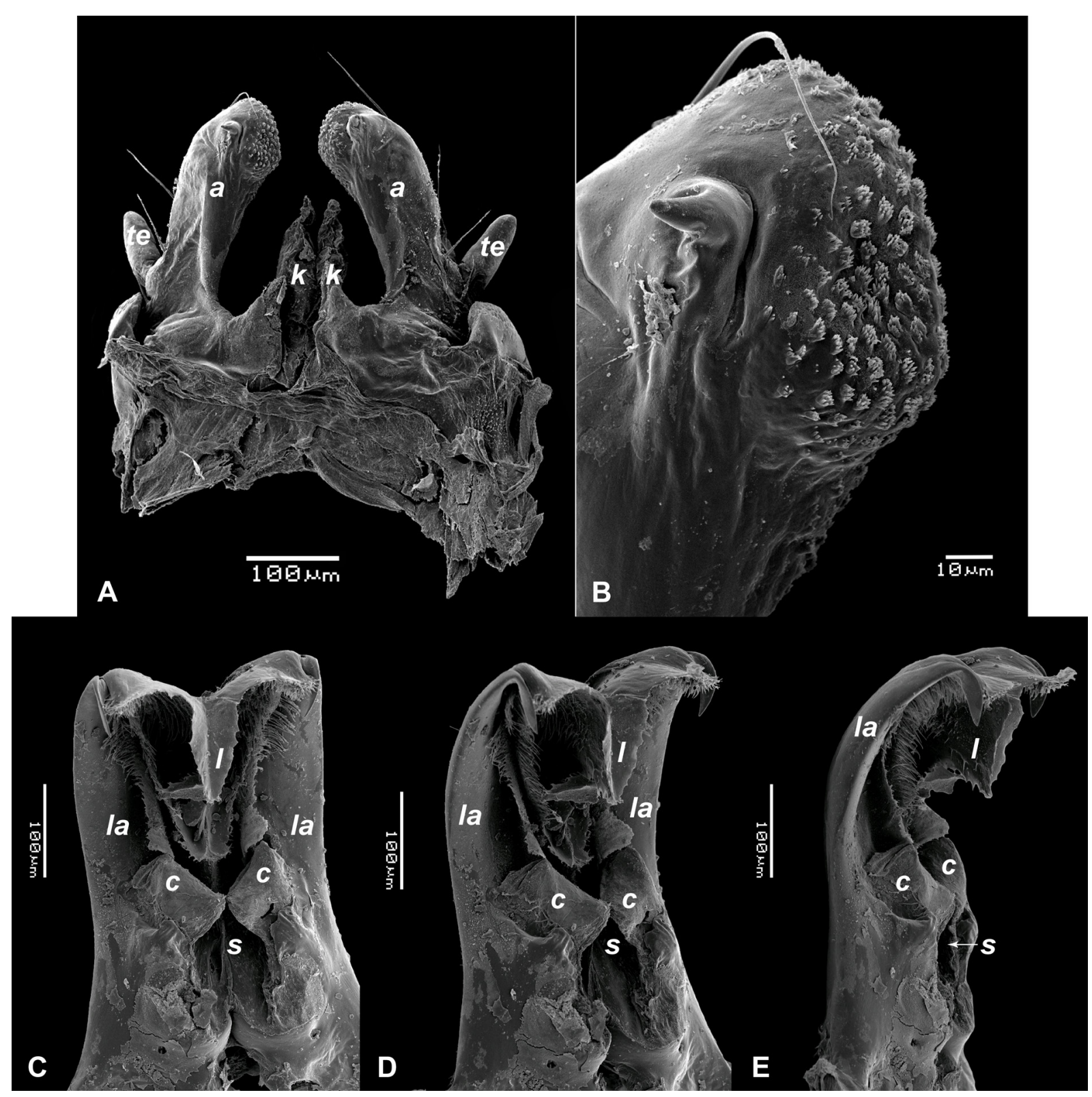

Fig. 7. Gonopods of Anamastigona terraesanctae Golovatch \& Makarov, 2011, §, non-type from Israel, the vicinity of Binyamina. A. Posterior gonopods, frontal view. B. Apical part of left angiocoxite, frontal view. C. Anterior gonopods, caudal, slightly lateral view. D. Anterior gonopods, caudo-lateral view. E. Anterior gonopods, lateral, slightly caudal view. Abbreviations as in Fig. 3. 
3. Anterior gonopods with flagella A. matsakisi Mauriès \& Karamaouna, 1984

- Anterior gonopods without flagella

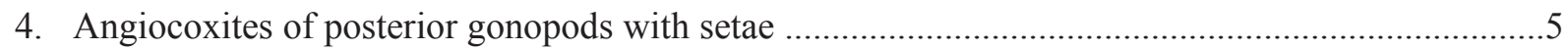

- Angiocoxites of posterior gonopods (excluding telopodital rudiments) without setae .....................9

5. Angiocoxites of posterior gonopods reaching approximately same level as both colpocoxites and telopodital rudiments

A. meridionalis Silvestri, 1898

- Angiocoxites of posterior gonopods considerably outreaching both colpocoxites and telopodital rudiments

6. Caudal face of anterior gonopods with neither setae nor fringes, nor spiculi

- Caudal face of anterior gonopods more or less densely pilose/spiculate

A. hispidula (Silvestri, 1895)

7. Lateral arms of anterior gonopods more or less straight, blunt apically A. strasseri sp. nov.

- Lateral arms of anterior gonopods bent strongly caudad, tapering apically .8

8. Colpocoxites of anterior gonopods short and robust; angiocoxites of posterior gonopods massive, somewhat bulging apically A. terraesanctae Golovatch \& Makarov, 2011

- Colpocoxites of anterior gonopods elongated, with membranous ends; angiocoxites of posterior gonopods rather slender, somewhat narrowing distally A. cypria sp. nov.

9. Angiocoxites of posterior gonopods very slender, finger- or horn-shaped .10

- Angiocoxites of posterior gonopods stouter, more massive

10. Apical parts of lateral arms of anterior gonopods directed mesad

A. radmani Makarov et al., 2007

- Apical parts of lateral arms of anterior gonopods directed laterad

11. Colpocoxites of posterior gonopods mostly to entirely fused into a single plate

A. pulchella (Silvestri, 1894)

- Colpocoxites of posterior gonopods well separated A. bilselii (Verhoeff, 1940)

12. Telopodital rudiments of posterior gonopods well-pronounced lobes

A. aspromontis (Strasser, 1970)

- Telopodital rudiments of posterior gonopods represented by rounded, weakly protruding bumps

13. Telopodital rudiments of posterior gonopods with one seta each

A. mediterranea Ćurčić, Makarov \& Lymberakis, 2001

- Telopodital rudiments of posterior gonopods without setae

A. penicillata (Attems, 1902)

14. Anterior gonopods with small telopodital rudiments placed parabasally on lateral arms A. albanensis Mauriès, Golovatch \& Stoev, 1997

- Anterior gonopods without telopodital rudiments

15. Position of ex-telopodites of posterior gonopods indicated by dark spots basally on angiocoxites

Angiocoxites of posterior gonopods without any trace of ex-telopodites

-Angiocoxites of posterior gonopods without any trace of ex-telopodites.... 
16. Angiocoxites of posterior gonopods with 2-3 setae apically

A. pentelicona (Verhoeff, 1925)

- Angiocoxites of posterior gonopods serrated apically, but without setae

A. hauseri (Strasser, 1974)

17. Median part of anterior gonopods represented by a single, trapezoid plate ...A. alba (Strasser, 1960)

- Median part of anterior gonopods distally divided in two symmetric parts

18. Both colpocoxites and median part of anterior gonopods setose/spinulate at margins

A. falcata (Gulička, 1967)

- Colpocoxites and median part of anterior gonopods without setiform or spiniform filaments ......

19. Angiocoxites of posterior gonopods about twice as long as colpocoxites, parallel to converging in their proximal parts

A. lepenicae (Strasser, 1975)

- Angiocoxites of posterior gonopods less than twice as long as colpocoxites, diverging right from their bases .....

A. delcevi (Strasser, 1973)

\section{Discussion}

Anamastigona terraesanctae, A. cypria sp. nov. and A. strasseri sp. nov. appear to be a natural group characterized by the above described diagnostic features, as well as by generally similar morphometrics and colour pattern. This is yet another example of the considerable similarity between the millipede faunas of Cyprus and the Levant (Vagalinski et al. 2014). Interestingly, A. strasseri sp. nov. seems to occupy a morphologically intermediate position between $A$. terraesanctae and $A$. cypria sp. nov., sharing the uniramous lateral arms of the anterior gonopods and the stout, apically broad angiocoxites of the posterior gonopods with the former species, but the very long and dense pilosity on the median lamella and the elongated colpocoxites of the anterior gonopods with the latter.

At present, the exact number of species within Anamastigona remains uncertain. As already mentioned in the introduction, the proposed synonymy of A. aspromontis (Strasser, 1970) with A. meridionalis Silvestri, 1898 does not seem to be solid enough. There are a number of differences concerning the gonopodal apparatus that can hardly be considered as mere individual variations: the anterior gonopods in $A$. aspromontis have a more narrow median plate/lamella and bear two slender, apically branched processes positioned between the colpocoxites and the lamella, these being absent in A. meridionalis; and, most importantly, the posterior gonopods in A. meridionalis possess very small angiocoxites, about the same size as the telopodital rudiments, the former bearing several setae, vs the angiocoxites by far outreaching the telopodital rudiments and being devoid of setae in A. aspromontis. Moreover, the presence/absence of setae on the angiocoxites is considered an important diagnostic character by Ćurčić et al. (2008), since these authors used it in their identification key in several couplets concerning the species of Anamastigona. As regards A. halophila, it is not recognized as a valid species in the present study, although the unknown conformation of the posterior gonopods in the single known male leaves a certain amount of uncertainty about its possible synonymy with $A$. bilselii (Verhoeff, 1940).

The inner grouping of Anamastigona is currently almost completely unresolved, with the only recent consideration on the topic being that by Makarov et al. (2007), who divided the genus into two groups based on the presence/absence of telopodites on the posterior gonopods and the shape of their angiocoxites. According to their study, the Bulgarian endemics A. falcata (Gulička, 1967), A. alba (Strasser, 1960), A. lepenicae (Strasser, 1975) and A. delcevi (Strasser, 1973), possibly together with the Albanian A. albanensis Mauriès, Golovatch \& Stoev, 1997, form a species group separate from the rest of their congeners. However, in such a division A. hauseri (Strasser, 1974) and A. pentelicona (Verhoeff, 1925) should also join the first group, since their telopodites are completely reduced, with only some pigmented spots/granules indicating the position of the lost appendages, like the condition observed in 


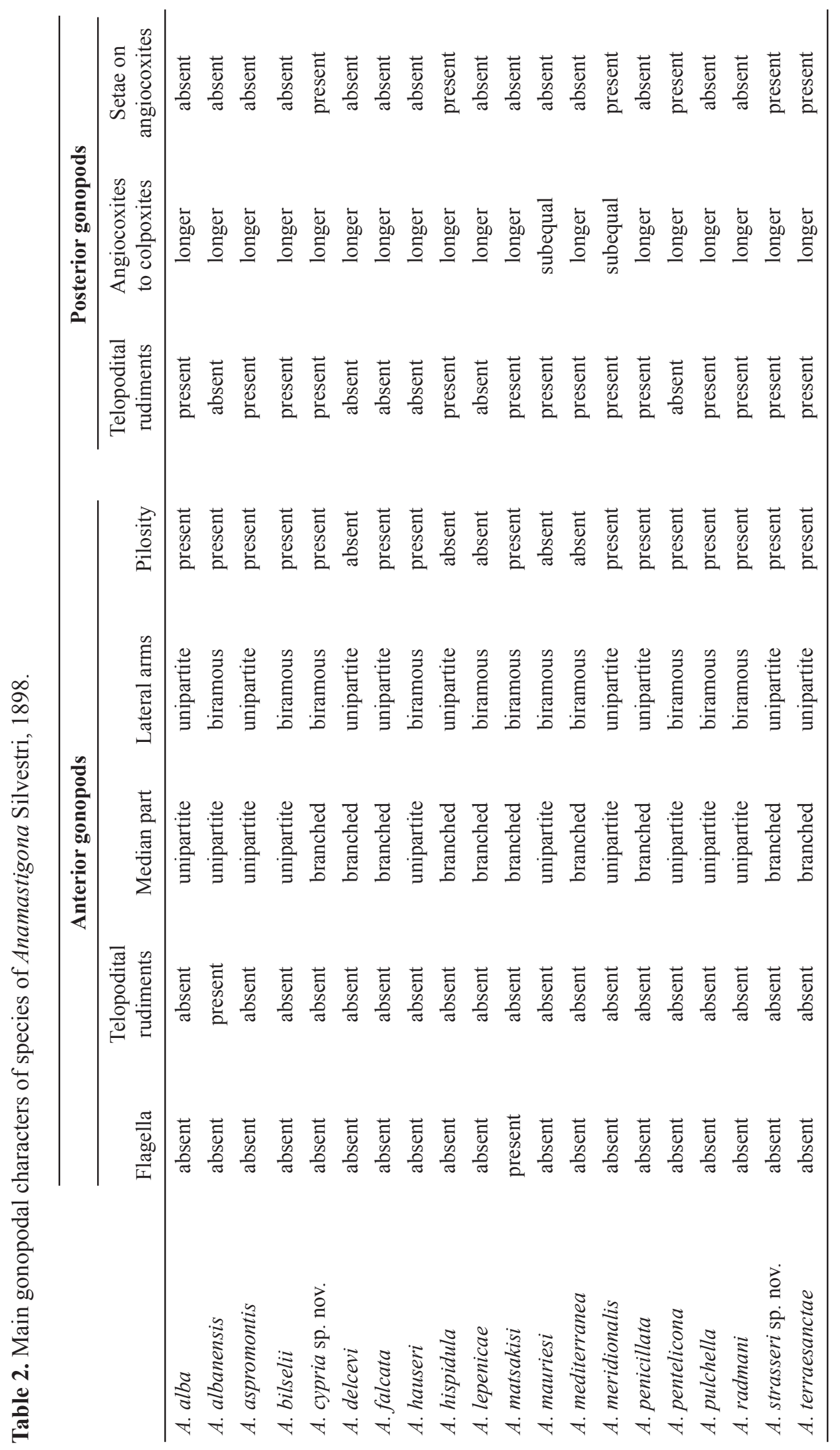


A. albanensis. On the other hand, unlike the Bulgarian species, which possess very slender, hornlike angiocoxites, the posterior gonopods in A. albanensis, A. hauseri and A. pentelicona are considerably less-strongly modified. A strongly elongated shape of the angiocoxites is also present in A. bilselii (Verhoeff, 1940) and A. radmani Makarov et al., 2007, although they bear well-pronounced telopodital rudiments. The several main diagnostic gonopodal characters applied in the key by Curčić et al. (2008) and in the present one are of little help for any clear intrageneric division to be proposed. Most of the presumable derived characters (e.g., absence of telopodital rudiments on posterior gonopods or absence of setae on angiocoxites of anterior gonopods) are reductive in nature and thus likely to present homoplasies, rather than synapomorphies (see Table 2). A further difficulty is the presence of unique, probably plesiomorphic characters in certain species, like the anterior gonopods possessing flagella in A. matsakisi or telopodital rudiments in A. albanensis, both of these traits making it hard to compare them to the remaining congeners. Perhaps the most outstanding species of all is A. mauriesi: it displays a unique conformation of the posterior gonopods, which have unusually large colpocoxites and telopodital rudiments placed on top of the angiocoxites, the latter condition supposed to represent the most plesiomorphic state within the entire genus (Golovatch \& Makarov 2011). On the other hand, the considerably enlarged angiocoxites in combination with the strongly reduced, knot-like telopodites may be the result of a different course of modification of the posterior gonopods that might have taken place very early in the evolution of the genus. It is possible that future examination of vulval characters, which with very few exceptions are completely unknown in Anamastigona, could shed more light on the phylogenetic affinities of its constituent species.

Anamastigona is surely more speciose than we presently know. This can be assumed from the small size of the animals, combined with their supposed low surface activity, as well as from the overwhelmingly local endemism. Vast, insufficiently explored areas like the Mediterranean coast of Turkey and, especially, the Caucasus, the latter considered as a diversity hotspot for the entire family Anthroleucosomatidae (Mauriès et al. 1997; Golovatch \& Makarov 2011), are probably inhabited by a number of still undescribed members of the genus.

\section{Checklist of Anamastigona species}

Anamastigona alba (Strasser, 1960)

Distribution

Bulgaria (Enghoff \& Kime 2013).

Anamastigona albanensis Mauriès, Golovatch \& Stoev, 1997

Distribution

Albania (Enghoff \& Kime 2013).

Anamastigona aspromontis (Strasser, 1970)

Distribution

Italian mainland (Enghoff \& Kime 2013).

Anamastigona bilselii (Verhoeff, 1940)

Distribution

Bulgaria (Strasser 1973), European Turkey, Greek mainland (Enghoff \& Kime 2013).

Anamastigona cypria sp. nov.

Distribution

Cyprus. 
Anamastigona delcevi (Strasser, 1973)

Distribution

Bulgaria (Enghoff \& Kime 2013).

Anamastigona falcata (Gulička, 1967)

Distribution

Bulgaria (Enghoff \& Kime 2013).

Anamastigona hauseri (Strasser, 1974)

Distribution

Greek mainland (Enghoff \& Kime 2013).

Anamastigona hispidula (Silvestri, 1895)

A. napolitana (Attems, 1899)

A. apenninorum (Verhoeff, 1930)

A. hispidula ischiana (Verhoeff, 1940)

A. hiemalis (Verhoeff, 1941)

A. hispidula quercuum (Verhoeff, 1942)

A. hispidula relicta (Verhoeff, 1942)

A. hispidula epomeana (Verhoeff, 1952)

Distribution

Italy: mainland (Enghoff \& Kime 2013), Capri (Verhoeff 1942), Ischia (Verhoeff 1940a, 1941).

Anamastigona lepenicae (Strasser, 1975)

Distribution

Bulgaria (Enghoff \& Kime 2013).

Anamastigona matsakisi Mauriès \& Karamaouna, 1984

Distribution

Greece: Naxos (Mauriès \& Karamaouna, 1984).

Anamastigona mauriesi Golovatch \& Makarov, 2011

Distribution

Autonomous Republic of Abkhazia (Golovatch \& Makarov 2011).

Anamastigona mediterranea Ćurčić, Makarov \& Lymberakis, 2001

Distribution

Greece: Crete (Enghoff \& Kime 2013).

Anamastigona meridionalis Silvestri, 1898

Distribution

Italy: Sicily (Enghoff \& Kime 2013).

Anamastigona penicillata (Attems, 1902)

Distribution

Greece: Crete (Enghoff \& Kime 2013).

Anamastigona pentelicona (Verhoeff, 1925)

Distribution

Greek mainland (Enghoff \& Kime 2013). 
Anamastigona pulchella (Silvestri, 1894)

A. attemsi (Verhoeff, 1900)

A. macchiae (Verhoeff, 1930)

Distribution

Italian mainland, French mainland, Madeira, Northern Ireland (Enghoff \& Kime 2013), Germany (Lindner et al. 2010).

Anamastigona radmani Makarov et al., 2007

Distribution

Croatia (Makarov et al. 2007).

Anamastigona strasseri sp. nov.

Distribution

Cyprus.

Anamastigona terraesanctae Golovatch \& Makarov, 2011

Distribution

Israel (Golovatch \& Makarov 2011).

\section{Acknowledgements}

We are most thankful to Stylianos Simaiakis (NHMC) and to Kirill Mikhailov (ZMUM) for making specimens under their care available for study. Yordan Keremidchiev (Sofia, Bulgaria) skillfully refined the SEM- and stereo microscopic pictures.

\section{References}

Attems C. 1899. Neues über paläarktische Myriopoden. Zoologische Jahrbücher, Abteilung für Systematik, Ökologie und Geographie der Tiere 12: 286-336.

Ćurčić B.P.M., Makarov S.E., Tomić V.T., Mitić B.M., Ćurčić S.B., Dudić B.D., Lučić L.R. \& Jasnić N. 2008. On a new genus of endemic millipedes (Diplopoda: Chordeumatida: Anthroleucosomatidae) from the Balkan Peninsula. Zootaxa 1743: 1-16.

Enghoff H. \& Kime R.D. 2013. Fauna Europaea: Diplopoda. Fauna Europaea version 2.6.2. Available from: http://www.faunaeur.org [accessed 31 Mar. 2016]

Golovatch S.I. \& Makarov S.E. 2011. Two new, easternmost species of the millipede genus Anamastigona Silvestri, 1898 from Israel and the Caucasus (Diplopoda, Chordeumatida, Anthroleucosomatidae). Arthropoda Selecta 20 (1): 11-20.

Gulička J. 1967. Neue und interessante Diplopoden aus Bulgarien. Annotationes Zoologicae et Botanicae (Bratislava) 39: 1-9.

Lindner E.N., Reip H.S. \& Spelda J. 2010. Anamastigona pulchella (Silvestri, 1898) (Diplopoda: Chordeumatida: Anthroleucosomatidae) - ein für Deutschland neuer Tausendfüßer. Schubartiana 4: $1-8$.

Makarov S.E., Rađa T., Rađa B., Tomić V.T., Mitić B.M. \& Ćurčić B.P.M. 2007. Anamastigona radmani sp. n. (Diplopoda, Anthroleucosomatidae) from Croatia. Biologia (Bratislava) 62 (5): 581-587.

Mauriès J.-P. \& Karamaouna M. 1984. Myriapodes-Diplopodes nouveaux et peu connus des îles Naxos, Paros et Antiparos (Cyclades, Grèce). Biologia Gallo-Hellenica 11: 51-59. 
Mauriès J.-P., Golovatch S.I. \& Stoev P.E. 1997. The millipedes of Albania: recent data, new taxa; systematical, nomenclatural and faunistical review (Myriapoda, Diplopoda). Zoosystema 19 (2-3): 255-292.

Silvestri F. 1898. Contributo alla conosceza dei Diplopodi della fauna mediterranea. Annali del Museo civico di Storia naturale di Genova 18 (2): 654-669.

Strasser K. 1960. Diplopoden aus Alpen-, Apenninen- und Balkanländern. Fragmenta Entomologica 3 (6): 95-140.

Strasser K. 1970. Diplopodi della Sicilia e della Calabria. Memorie del Museo civico di Storia naturale di Verona 17: 151-200.

Strasser K. 1973. Über Diplopoden Bulgariens, III. Annales Zoologici 30 (15): 411-470.

Vagalinski B., Golovatch S., Simaiakis S.M., Enghoff H. \& Stoev P. 2014. Millipedes of Cyprus (Myriapoda: Diplopoda). Zootaxa 3835 (4): 528-548. http://dx.doi.org/10.11646/zootaxa.3835.4.5

Verhoeff K. 1940a. Über einige Diplopoden, Chilo- und Isopoden der Insel Ischia. Zoologischer Anzeiger 131: 271-287.

Verhoeff K. 1940b. Über Diplopoden aus der Türkei. Istanbul Üniversitesi fen Fakültesi Mecmuasi 5 (1-2): 1-49.

Verhoeff K. 1941. Diplopoden der Insel Ischia, systematisch, morphologisch, phänologisch, ökologisch, geographisch. Zeitschrift für Morphologie und Ökologie der Tiere 38 (1): 147-196.

Verhoeff K. 1942. Diplopoden der Insel Kapri. Zoologischer Anzeiger 139 (11-12): 213-233.

Manuscript received: 29 January 2016

Manuscript accepted: 6 April 2016

Published on: 6 September 2016

Topic editor: Rudy Jocqué

Desk editor: Danny Eibye-Jacobsen

Printed versions of all papers are also deposited in the libraries of the institutes that are members of the EJT consortium: Muséum national d'Histoire naturelle, Paris, France; Botanic Garden Meise, Belgium; Royal Museum for Central Africa, Tervuren, Belgium; Natural History Museum, London, United Kingdom; Royal Belgian Institute of Natural Sciences, Brussels, Belgium; Natural History Museum of Denmark, Copenhagen, Denmark; Naturalis Biodiversity Center, Leiden, the Netherlands. 